\title{
Multi-Spectroscopic and Theoretical Analysis on the Interaction between Human Serum Albumin and a Capsaicin Derivative-RPF101
}

\author{
Otávio Augusto Chaves ${ }^{1,2}$, Maurício Temotheo Tavares ${ }^{3}$ (D), Micael Rodrigues Cunha ${ }^{3}$ (D), \\ Roberto Parise-Filho $^{3}$ (D) , Carlos Maurício R. Sant'Anna ${ }^{1}$ and José Carlos Netto-Ferreira ${ }^{1,4, *}$ \\ 1 Institute of Chemistry, Universidade Federal Rural do Rio de Janeiro, BR-465 Km 7, \\ 23970-000 Seropédica-RJ, Brazil; otavioaugustochaves@gmail.com (O.A.C.); santana@ufrrj.br (C.M.R.S.) \\ 2 SENAI Innovation Institute for Green Chemistry, Rua Morais e Silva $N^{\circ}$ 53, Maracanã, \\ 20271030 Rio de Janeiro-RJ, Brazil \\ 3 Department of Pharmacy, University of São Paulo, Prof. Lineu Prestes Avenue, 580, Bl.13, \\ 05508-900 Butanta, São Paulo-SP, Brazil; mauricio.tavares@usp.br (M.T.T.); micaelrc@usp.br (M.R.C.); \\ roberto.parise@usp.br (R.P.-F.) \\ 4 National Institute of Metrology, Quality and Technology, 25250-020 Duque de Caxias-RJ, Brazil \\ * Correspondence: jcnetto.ufrrj@gmail.com; Tel.: +55-21-96498-4628
}

Received: 14 July 2018; Accepted: 16 August 2018; Published: 23 August 2018

\begin{abstract}
The interaction between the main carrier of endogenous and exogenous compounds in the human bloodstream (human serum albumin, HSA) and a potential anticancer compound (the capsaicin analogue RPF101) was investigated by spectroscopic techniques (circular dichroism, steady-state, time-resolved, and synchronous fluorescence), zeta potential, and computational method (molecular docking). Steady-state and time-resolved fluorescence experiments indicated an association in the ground state between HSA:RPF101. The interaction is moderate, spontaneous $\left(\Delta G^{\circ}<0\right)$, and entropically driven $\left(\Delta S^{\circ}=0.573 \pm 0.069 \mathrm{~kJ} / \mathrm{molK}\right)$. This association does not perturb significantly the potential surface of the protein, as well as the secondary structure of the albumin and the microenvironment around tyrosine and tryptophan residues. Competitive binding studies indicated Sudlow's site I as the main protein pocket and molecular docking results suggested hydrogen bonding and hydrophobic interactions as the main binding forces.
\end{abstract}

Keywords: human serum albumin; RPF101; capsaicin; multi-spectroscopy; molecular docking

\section{Introduction}

Capsaicin is a major component of red pepper, being reported as a potent anticancer compound [1] However, due to its intrinsic pungent effect through transient receptors potential vanilloid type 1 (TRPV1) [2], to date the therapeutic use of capsaicin is restricted to pain relief by topical application [3]. Using strategies of ligand-based drug design, Tavares et al. [4] and Damião et al. [5] developed a wide number of capsaicin derivatives aiming to enhance their anticancer profile [6,7]. Interestingly, among the active compounds, $N$-(benzo[ $d][1,3]$ dioxol-5-ylmethyl) benzenesulfonamide (RPF101, Figure 1) was revealed as a prominent cytotoxic compound, being active against five different breast and skin cancer cell lines, with no associated pungency in vivo [4]. RF101 can induce arrest of the cell cycle at the G2/M phase through a disruption of the microtubule network. Furthermore, it can cause cellular morphologic changes characteristic of apoptosis and a decrease of mitochondrial membrane potential $(\Delta \psi \mathrm{m})[4]$.

Serum albumin (SA) is the most abundant protein in mammalian blood plasma, being synthesized in the liver, where it is produced at a rate of approximately $0.7 \mathrm{mg} / \mathrm{h}$ for every gram of liver (i.e., 
10-15 g daily) [8]. Due to its high concentration and to the presence of multiple binding pockets, SA is a major transporter of endogenous compounds, including fatty acids, hormones, and metal ions [9]. Human serum albumin (HSA) is the most abundant protein that is present in the human circulatory system (35-50 g/L), having an average half-life of 19 days. The three-dimensional structure of HSA has been elucidated by $\mathrm{X}$-ray analysis and revealed a non-glycosylated heart shaped molecule (66.5 kDa), with dimensions of $80 \AA \times 80 \AA \times 80 \AA \times 30 \AA$ (Figure 1) [10,11]. Human serum albumin structure is composed by three structurally similar domains I-III, each one consisting of two subdomains (A and B), stabilized by 17 disulfide bridges [12]. Human serum albumin is an acidic, very soluble protein that is extremely robust: it is stable in the $\mathrm{pH}$ range of $4-9$, soluble in $40 \%$ ethanol, and can be heated at $60{ }^{\circ} \mathrm{C}$ for up to $10 \mathrm{~h}$ without deleterious effects. These properties as well as its preferential uptake in tumor and inflamed tissue, ready availability, biodegradability, and the lack of toxicity and immunogenicity make it an ideal candidate for drug delivery [13]. In addition, as most drugs have a poor pharmacokinetic profile and are generally non-specifically distributed in the human body, sometimes causing serious side effects, the development of drug delivery systems intended to specifically target a tumor site becomes a very important issue. When considering that RPF101 is a promising anticancer agent and that albumin is the major component in passive and active tumor targeting in the drug delivery process, the study of the interaction between HSA and RPF101 is of extreme relevancy $[14,15]$.

The present work reports a study of the interaction between HSA and the capsaicin derivative RPF101 using multi-spectroscopic techniques (circular dichroism, steady state, time-resolved, and synchronous fluorescence), zeta potential, and theoretical calculations (molecular docking). Each of the techniques that are employed in this work makes a significant contribution to the understanding of the binding process. The steady-state fluorescence technique indicates the characteristics of the photophysical process that is associated with the HSA:ligand interaction, as well as on the thermodynamic parameters involved in this interaction. On the other hand, time resolved fluorescence is one of the most sensitive spectroscopic techniques and it allows for confirming which main mechanism is operating in the fluorescence quenching process, whereas the structural perturbation that occurs in the microenvironment around the amino acid residues Tyr (tyrosine) and Trp (tryptophan) can be investigated using the synchronous fluorescence technique. Additional information on both the secondary structure and the albumin surface perturbation after ligand binding can be obtained while using the circular dichroism and zeta potential techniques. Finally, molecular modeling may suggest the major binding forces and amino acid residues involved in the interaction between HSA and RPF101. These results will offer a comprehension on the interaction mechanism between HSA-the main carrier of endogenous and exogenous molecules-and the natural product analogue RPF101, contributing to an understanding of distribution and transport involved in the behavior of the cytotoxic compound RPF101—one of the main steps in drug development [16]. 

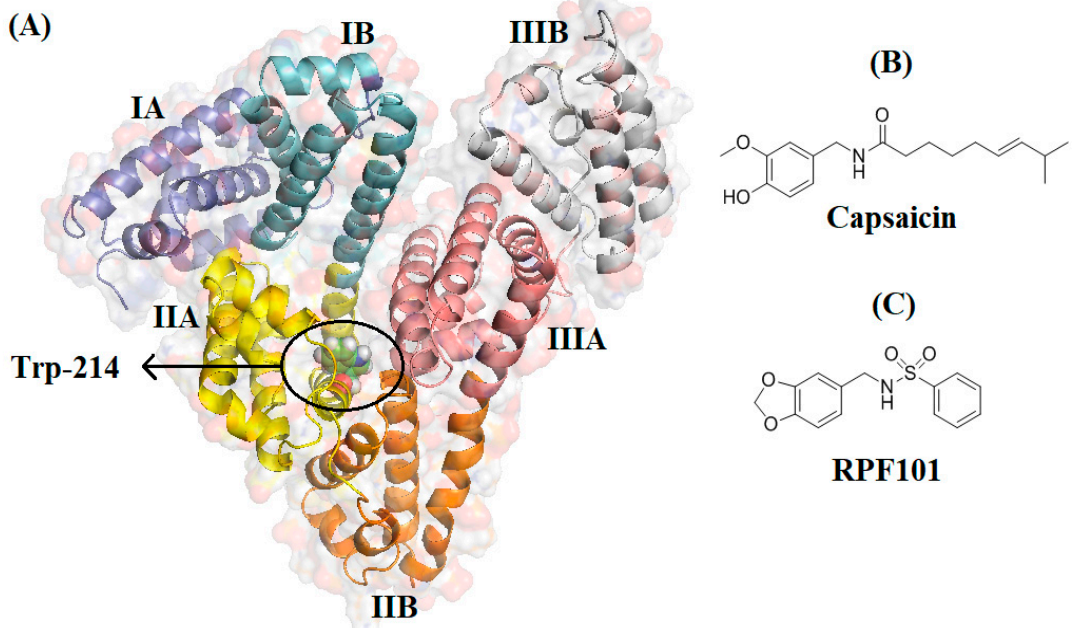

(C)

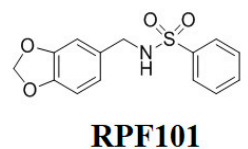

Figure 1. (A) Human serum albumin (HSA) structure as cartoon representation and tryptophan-214 (Trp-214) residue as green stick. (B,C) Chemical structure of capsaicin and its analogue RPF101.

\section{Materials and Methods}

\subsection{Chemicals}

Commercially available HSA, warfarin, ibuprofen, digitoxin, and phosphate-buffered saline (PBS) ( $\mathrm{pH}=7.4$ ) were purchased from Sigma-Aldrich (São Paulo, SP, Brazil). Phosphate-buffered saline solution was obtained by dissolving one tablet in $200 \mathrm{~mL}$ of deionized water, yielding $1.00 \times 10^{-2} \mathrm{M}$ of phosphate buffer containing $2.70 \times 10^{-3} \mathrm{M}$ potassium chloride and $1.37 \times 10^{-1} \mathrm{M}$ sodium chloride- $-\mathrm{pH} 7.4$ at $298 \mathrm{~K}$. Water used in all the experiments was millipore grade. Methanol (spectroscopic grade) was obtained from Vetec Quimica Fina Ltd. (Rio de Janeiro, RJ, Brazil). The compound RPF101 was synthesized following the procedure that was described in the literature [4]. Briefly, triethylamine and dimethylformamide were added to a dichloromethane solution of piperonylamine. Then benzenesulfonyl chloride $(5.0 \mathrm{mmol})$ was added dropwise under nitrogen atmosphere and stirred for $24 \mathrm{~h}$ at room temperature. The organic layer was thoroughly washed, dried over $\mathrm{MgSO}_{4}$, and the solvent was removed under high vacuum. The product RPF101 was obtained after recrystalization from hot hexane:dichloromethane, resulting in a white solid $(80.2 \%$ yield) with a melting point (m.p.) $=77.1-77.6^{\circ} \mathrm{C}[4]$.

\subsection{Steady-State Fluorescence Measurements}

Steady-state fluorescence was measured on a Jasco J-815 fluorimeter in a quartz cell $(1 \mathrm{~cm}$ optical path), employing a thermostated cuvette holder Jasco PFD-425S15F (JascoEaston, MD, USA). All spectra were recorded with appropriate background corrections, with number of averaging of three scans for each recorded. In order to compensate the inner filter effect (see Figure S1 in the Supplementary Material), the steady-state fluorescence intensity values for the association HSA:RPF101 was corrected through the absorption of RPF101 at excitation and emission wavelengths, according to Equation (1) [17]:

$$
F_{c o r}=F_{o b s} 10^{\left[\left(A_{e x}+A_{e m}\right) / 2\right]}
$$

where, $F_{c o r}$ and $F_{o b s}$ are the corrected and observed steady-state fluorescence intensity values, respectively. $A_{e x}$ and $A_{e m}$ are the experimental absorbance value at the excitation (molar extinction coefficient at $280 \mathrm{~nm}-\varepsilon=10,364 \mathrm{M}^{-1} \mathrm{~cm}^{-1}$ ) and emission wavelength (molar extinction coefficient at $340 \mathrm{~nm}-\varepsilon=808.75 \mathrm{M}^{-1} \mathrm{~cm}^{-1}$ ), respectively. 
The steady-state fluorescence spectra were measured in the 290-450 nm range, at 296, 303, and $310 \mathrm{~K}$, with excitation wavelength at $280 \mathrm{~nm}$. To a $3.0 \mathrm{~mL}$ solution containing an appropriate concentration of HSA $\left(1.00 \times 10^{-5} \mathrm{M}\right)$, successive aliquots from a stock solution of RPF101 $\left(1.00 \times 10^{-3} \mathrm{M}\right.$ in methanol) were added, with final concentrations of $0.17 ; 0.33 ; 0.50 ; 0.66 ; 0.83$; $0.99 ; 1.15 ; 1.32 \times 10^{-5} \mathrm{M}$. The addition was done manually by using a micro syringe. To investigate a possible perturbation on the steady-state fluorescence and circular dichroism spectra for HSA by adding methanol (solvent used for RPF101), these spectra were recorded without and in the presence of $40 \mu \mathrm{L}$ of this solvent. No significant effect was observed in both cases (see Figure S2 in the Supplementary Material).

\subsection{Time-Resolved Fluorescence Measurements}

Time-resolved fluorescence measurements were performed in a model FL920 CD Edinburgh Instruments fluorimeter (Edinburgh, UK) equipped with an electrically pumped laser (EPL) $\left(\lambda_{\text {exc }}=280 \pm 10 \mathrm{~nm}\right.$; pulse of 850 ps with energy of $1.8 \mu \mathrm{W} /$ pulse; monitoring emission at $\left.340 \mathrm{~nm}\right)$. The time range was fixed for $80 \mathrm{~ns}$, with channels 512 (time/ch $=0.09766 \mathrm{~ns}$ ) and peak counts of 700 counts. Fluorescence decay was obtained for the free HSA solution $\left(1.00 \times 10^{-5} \mathrm{M}\right.$ in PBS) and for a HSA solution containing the maximum concentration of RPF101 used in the steady-state fluorescence studies $\left(1.32 \times 10^{-5} \mathrm{M}\right)$ at room temperature (ca. $\left.298 \mathrm{~K}\right)$. The instrument response function (IRF) was obtained through the suspension of titanium dioxide $\left(\mathrm{TiO}_{2}\right)$ in a mix of glycerol and distilled water (proportion 1:5).

\subsection{Synchronous Fluorescence Measurements}

Synchronous fluorescence (SF) spectra were performed in a model Xe900 Edinburgh Instruments fluorimeter (Edinburgh, UK). Synchronous fluorescence spectrum for HSA $\left(1.00 \times 10^{-5} \mathrm{M}\right)$ was recorded with increasing concentration of RPF101 in the same concentration range that was used in the steady-state fluorescence studies. The spectra were recorded in the $245-320 \mathrm{~nm}$ range by setting constant wavelength interval, $\Delta \lambda=60 \mathrm{~nm}$ and $\Delta \lambda=15 \mathrm{~nm}$ for tryptophan and tyrosine residues, respectively, at room temperature (ca. $298 \mathrm{~K}$ ).

\subsection{Zeta Potential Measurements}

The surface charge of HSA in the absence and presence of RPF101 was characterized in terms of zeta potential (ZP), using a NanoBrookZetaPALS (Brookhaven Instruments, New York, NY, USA). All measurements were performed with 10 runs at room temperature (ca. $298 \mathrm{~K}$ ) and the results were reported in terms of $\mathrm{ZP} \pm \mathrm{SD}$, where $\mathrm{SD}$ is the standard deviation. The $\mathrm{ZP}$ was measured for HSA solution $\left(1.00 \times 10^{-5} \mathrm{M}\right.$ in PBS solution) without and in the presence of the maximum ligand concentration being used in the steady-state fluorescence experiments $\left(1.32 \times 10^{-5} \mathrm{M}\right)$ at room temperature (ca. $298 \mathrm{~K}$ ).

\subsection{Circular Dichroism Measurements}

Circular dichroism (CD) spectra were measured on a Jasco J-815 spectrometer (Easton, MD, USA), in a $1 \mathrm{~cm}$ quartz cell, employing a Jasco PFD-425S15F thermostated cuvette holder. All the spectra were recorded with appropriate background corrections. CD spectra were measured in the 200-260 nm range, at $310 \mathrm{~K}$, using a $1.0 \mathrm{~cm}$ path length quartz cuvette, with a $1.0 \mathrm{~nm}$ step resolution, and a response time of $1.0 \mathrm{~s}$. The spectra were collected and averaged over three scans. All spectra were baseline corrected by a control sample $(3.0 \mathrm{~mL}$ of buffer $+40 \mu \mathrm{L}$ of methanol). Firstly, the spectrum of a free HSA solution (1.00 $\times 10^{-6} \mathrm{M}$ in PBS solution) was recorded and then the spectrum resulting from the addition of the amount of RPF101 to obtain the maximum concentration used in the steady-state fluorescence experiments $\left(1.32 \times 10^{-5} \mathrm{M}\right)$ to the HSA solution was also recorded. 


\subsection{Drug Displacement Experiment}

Competitive binding studies were carried out with three probes widely employed for the characterization of binding sites in HSA, i.e., warfarin, ibuprofen, and digitoxin for site I, II, and III, respectively [18]. HSA and site probes were used at a fixed concentration $\left(1.00 \times 10^{-5} \mathrm{M}\right.$-proportion 1:1) and the fluorescence quenching titration with RPF101 was performed, as described previously in the steady-state fluorescence quenching method at $310 \mathrm{~K}$.

\subsection{Molecular Docking Studies}

The crystallographic structure of HSA was obtained from the Protein Data Bank (PDB) with access code 1N5U [19]. This structure has a resolution of $1.90 \AA$. The RPF101 structure was built and energy-minimized with the density functional theory (DFT), method Becke-3-Lee Yang Parr (B3LYP) with the standard 6-31G* basis set available in the Spartan'14 program (Wavefunction, Inc., Irvine, CA, USA). Molecular docking was performed with the GOLD 5.2 program (CCDC) [20]. The scoring function used was 'ChemPLP', which is the default function of the GOLD 5.2 program [21]. Hydrogen atoms were added to HSA according to the data inferred by GOLD 5.2 program on the ionization and tautomeric states. Docking interaction cavity in the protein was established with a $10 \AA$ radius from the Trp-214 residue. The number of genetic operations (crossover, migration, mutation) in each docking run that was used in the search procedure was set to 100,000. The figure of the best docking pose for each sample was generated by the PyMOL Delano Scientific LLC program. Further details can be found in previous publications $[17,22]$.

\section{Results}

\subsection{Steady-State and Time-Resolved Fluorescence Quenching}

According to the literature, of the twenty naturally occurring amino acids that make all proteins, three of them contain aromatic ring side chains, and therefore are intrinsically able to display fluorescence emission: Trp, Tyr, and phenylalanine (Phe). Upon $280 \mathrm{~nm}$ excitation, the fluorescence from albumin is originated mainly from the dominant source of absorption and emission-the indole group of tryptophan residues $\left(\varepsilon=5600 \mathrm{M}^{-1} \mathrm{~cm}^{-1}\right)$ — compared with phenylalanine $\left(\varepsilon=200 \mathrm{M}^{-1} \mathrm{~cm}^{-1}\right)$ or tyrosine $\left(\varepsilon=1400 \mathrm{M}^{-1} \mathrm{~cm}^{-1}\right)$ [23]. Human serum albumin has a single tryptophan residue (Trp-214) that is located in a hydrophobic cavity inside the subdomain IIA, known as Sudlow's site I. The intrinsic fluorescence emitted by Trp-214 is very sensitive to the environment around this amino acid residue. Tryptophan fluorescence has been employed frequently in the study of HSA interaction with different biological molecules, i.e., fatty acids and commercial and potential drugs [12,19]. Previous studies have shown that a solution of HSA in PBS $(\mathrm{pH}=7.4$ ) has a strong fluorescence emission at $340 \mathrm{~nm}$ when excited at $280 \mathrm{~nm}$ [24]. Successive addition of RPF101 to the HSA solution led to the effective fluorescence quenching of Trp-214, while both emission maximum and peak shape remained largely unchanged (Figure 2). This result indicates that the ligand can quench the internal fluorescence of the albumin and the absence of significant blue or red shift in the maximum of fluorescence is indicative that RPF101 does not change the environment in the vicinity of the fluorophores [21]. 


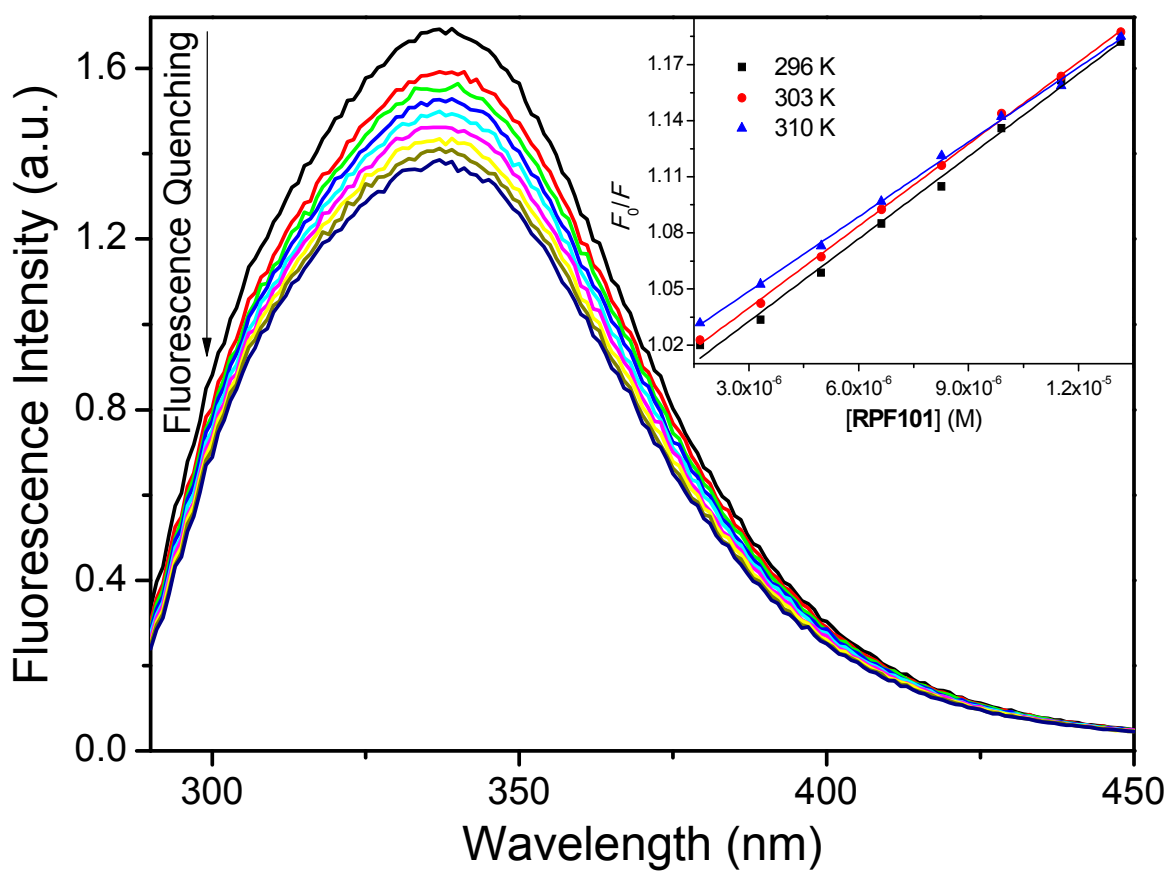

Figure 2. Steady-state fluorescence emission spectra for free human serum album (HSA) and its fluorescence quenching by addition of successive aliquots of RPF101 in phosphate-buffered saline (PBS) solution at $310 \mathrm{~K}$. [HSA] $=1.00 \times 10^{-5} \mathrm{M}$ and $[$ RPF101] $=0.17 ; 0.33 ; 0.50 ; 0.66 ; 0.83 ; 0.99 ; 1.15$; $1.32 \times 10^{-5} \mathrm{M}$. Inset: Stern-Volmer plots for the fluorescence quenching of HSA by RPF101 at 296, 303 and $310 \mathrm{~K}$.

A variety of molecular interactions can result in two different quenching mechanisms of a fluorescent species, i.e., dynamic or static. These interactions include ground-state complex formation, collisional quenching, excited state reactions, molecular rearrangement and energy transfer. Dynamic and static quenching can be distinguished by their different dependence on temperature and viscosity, or preferably by lifetime measurements [25]. In general, Stern-Volmer analysis (Equation (2) and inset in the Figure 2), as well as the known relationship between $k_{q}$ and $K_{S V}$ (Equation (3)), is useful in the estimation of the accessibility of the quencher molecule to the tryptophan residue in proteins as well as in the understanding of the mechanism that is involved in the quenching process [26]:

$$
\begin{gathered}
\frac{F_{0}}{F}=1+k_{q} \tau_{0}[Q]=1+K_{S V}[Q] \\
k_{q}=\frac{K_{S V}}{\tau_{0}}
\end{gathered}
$$

where, $F_{0}$ and $F$ are the fluorescence intensities of HSA without and in the presence of RPF101, respectively. $K_{S V}$ and $k_{q}$ are the Stern-Volmer quenching constant and bimolecular quenching rate constant, respectively. $[Q]$ is the RPF101 concentration and $\tau_{0}$ is the fluorescence lifetime of HSA without the presence of RPF101 - the measured mean value for the fluorescence lifetime of HSA was $(5.78 \pm 0.15) \times 10^{-9} \mathrm{~s}$; see time-resolved fluorescence studies.

Table 1 shows the $K_{S V}$ and $k_{q}$ values for HSA:RPF101. Since the obtained $K_{S V}$ values decrease with the increase of temperature and the bimolecular quenching rate constant values $\left(k_{q} \approx 10^{12} \mathrm{M}^{-1} \mathrm{~s}^{-1}\right)$ are three orders of magnitude larger than the diffusion rate constant $\left(k_{\text {diff }} \approx 7.40 \times 10^{9} \mathrm{M}^{-1} \mathrm{~s}^{-1}\right.$, at $298 \mathrm{~K}$, according to Smoluchowski-Stokes-Einstein theory) [27], the probable mechanism of fluorescence quenching is static, implying a ground-state association between the fluorophore (albumin) and the quencher (RPF101) [28]. In order to further confirm which type of fluorescence quenching mechanism is involved on the HSA:RPF101 interaction, time-resolved fluorescence measurements were performed 
for HSA without and in the presence of RPF101. Figure 3 depicts the fluorescence lifetime decay profiles for the native HSA and HSA associated with RPF101.

The fluorescence decays of HSA upon $280 \mathrm{~nm}$ excitation, at $\mathrm{pH} 7.4$, were well-fitted assuming two exponentials having lifetimes of $1.52 \pm 0.11 \mathrm{~ns}(22.0 \%)$ and $5.78 \pm 0.15 \mathrm{~ns}(78.0 \%)$ $\left(\chi^{2}=1.102\right)$. The experimental fluorescence lifetimes are in good agreement with the literature [29-31]. No significant changes in the HSA fluorescence lifetimes were observed in the presence of RPF101, when values of $1.58 \pm 0.14 \mathrm{~ns}$ and $5.72 \pm 0.13 \mathrm{~ns}\left(\chi^{2}=1.135\right)$ were obtained. Thus, the ratio between the fluorescence lifetimes of HSA in the absence and presence of RPF101 are close to unity, suggesting that the fluorescence quenching occurs through a static mechanism [32]. These results are in agreement with those that were obtained above by the Stern-Volmer analysis (Table 1).

There are two basic mechanisms for electronic energy transfer: electron exchange (Dexter) and dipole interaction (Förster). The efficiency of the former falls off exponentially with the distance between fluorophore and quencher, so it only operates at very short distances, essentially by contact; for the Förster mechanism, efficiency decreases with $1 / \mathrm{r}^{6}$, so it is still operational at $\sim 10 \AA$ [33]. Thus, Förster resonance energy transfer (FRET) is a non-radiative process: through-space coupling between the oscillating electronic dipole of the excited energy donor (Trp fluorophore in HSA) and that of the ground-state acceptor (quencher-RPF101) results in the de-excitation of the former and electronic excitation of the latter: transference of a "virtual", rather than "real" photon. As a result, the donor fluorophore returns to its ground state, without emission of fluorescence, while the acceptor quencher is promoted to its excited state [21]. Therefore, the quenching of the fluorophore by FRET can occurs if there is an overlap between the fluorophore emission and quencher absorption spectra. In Figure S3 in the Supplementary Material, such overlap between the fluorescence emission spectrum of HSA and the absorption spectrum of RPF101 can be clearly seen, indicating the possible occurrence of an energy transfer process between the fluorophore in protein and the ground state of RPF101 [34]. But, the absence of any change in the fluorescence lifetime of HSA after the addition of RPF101 indicates that FRET is not operating in the present case [23].
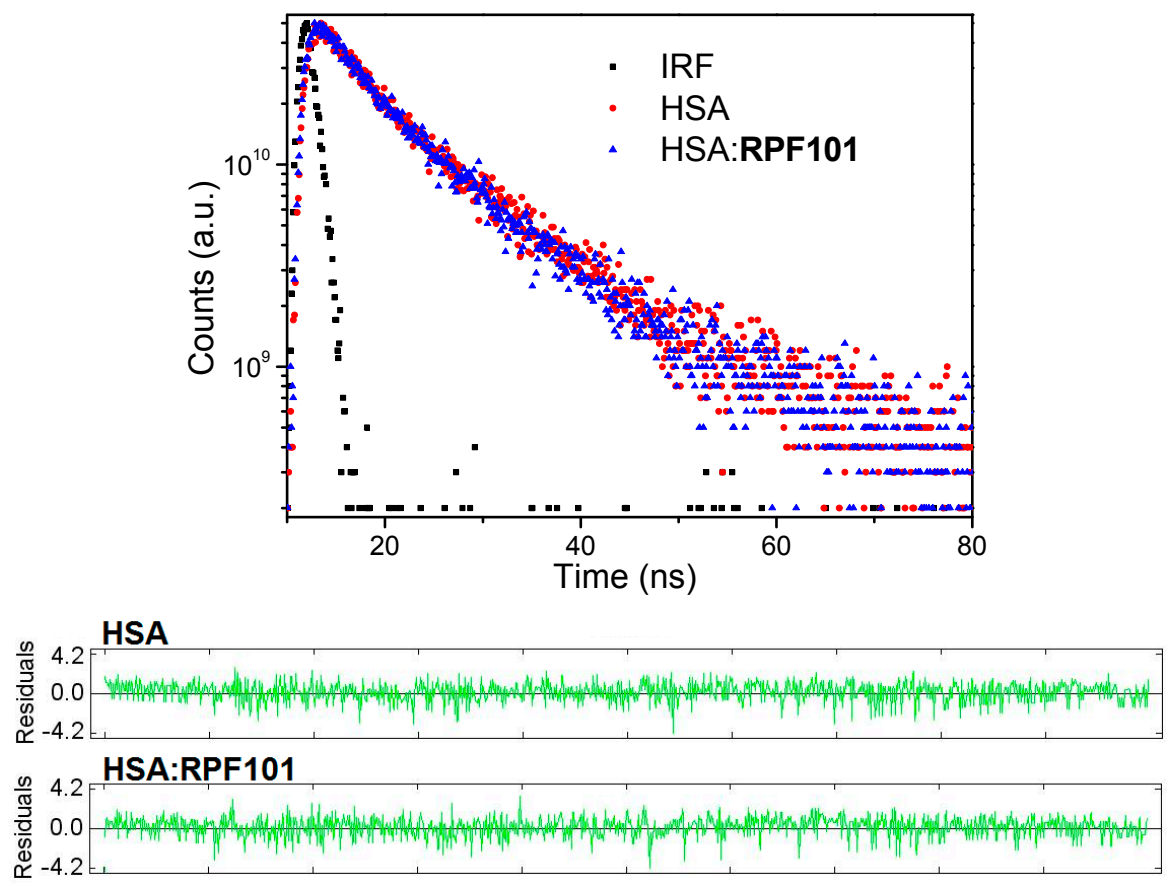

Figure 3. Time-resolved fluorescence decays and residuals for HSA without and in the presence of RPF101 in PBS solution, at room temperature. $[\mathrm{HSA}]=1.00 \times 10^{-5} \mathrm{M}$ and $\left[\right.$ RPF101] $=1.32 \times 10^{-5} \mathrm{M}$. 
From the pharmacological point of view, if the drugs are metabolized and excreted from the body too fast because of low protein binding, they will not be able to provide their therapeutic effects. On the other hand, if drugs bind too strongly to protein and are metabolized and excreted too slowly, the in vivo half-life of these drugs can increase excessively, and this may lead to undesired side effects and/or toxicity [35]. To obtain information about the association between HSA and RPF101, the modified Stern-Volmer binding constant $\left(K_{a}\right)$ was calculated while employing the Figure 4 and Equation (4):

$$
\frac{F_{0}}{F_{0}-F}=\frac{1}{f K_{a}[Q]}+\frac{1}{f}
$$

where, $F_{0}$ and $F$ are the fluorescence intensities of HSA without and in the presence of RPF101 at $340 \mathrm{~nm}$, respectively. [Q] is the RPF101 concentration and $f$ is the fraction of the initial fluorescence that is accessible to quenchers $(f \approx 1.00)$. The $K_{a}$ values for the association HSA:RPF101 are in the range of $10^{3}-10^{4} \mathrm{M}^{-1}$, showing a moderate interaction between the potential drug RPF101 and HSA [36,37] (Table 1), suggesting that RPF101 can be stored and carried by the protein in the human bloodstream [38,39]. The increase of $K_{a}$ values with the increase of temperature indicates that the protein structure can better accommodate the ligand at $310 \mathrm{~K}$ (human body temperature) than at $296 \mathrm{~K}$, which is probably due to binding pocket being more accessible by the quenchers at $310 \mathrm{~K}$.

In general, the main interaction forces between endogenous and exogenous molecules with proteins can include hydrophobic interaction, hydrogen bond, van der Waals, and electrostatic forces. These intermolecular interactions can be related to the thermodynamic parameters $\Delta G^{\circ}, \Delta H^{\circ}$ and $\Delta S^{\circ}[40]$, which can be obtained applying the van't Hoff analysis (Equation (5) and inset in the Figure 4) and the Gibbs free energy analysis (Equation (6)) [39].

$$
\begin{aligned}
\ln K_{a} & =-\frac{\Delta H^{\circ}}{R T}+\frac{\Delta S^{\circ}}{R} \\
\Delta G^{\circ} & =\Delta H^{\circ}-T \Delta S^{\circ}
\end{aligned}
$$

where, $\Delta H^{\circ}, \Delta S^{\circ}, \Delta G^{\circ}$ are the enthalpy, entropy, and Gibbs free energy change, respectively. $R$ is the gas constant $\left(R=8.314 \times 10^{-3} \mathrm{~kJ} / \mathrm{mol} \mathrm{K}\right), T$ is the temperature $(296,303$ and $310 \mathrm{~K})$, and $K_{a}$ the modified Stern-Volmer binding constant. Negative values for $\Delta G^{\circ}$ are in further accord with the spontaneity of the binding process between HSA and RPF101. The unfavorable positive $\Delta H^{\circ}$ can be compensated by the positive $\Delta S^{\circ}$, which indicate a hydrophobic interaction [41] and suggest that the binding process is entropically driven [42].

Table 1. Stern-Volmer quenching constant $\left(K_{S V}\right)$, bimolecular quenching rate constant $\left(k_{q}\right)$, modified

\begin{tabular}{|c|c|c|c|c|c|c|}
\hline $\mathrm{T}(\mathrm{K})$ & $K_{S V}\left(\mathrm{M}^{-1}\right)$ & $k_{q}\left(\mathrm{M}^{-1} \mathrm{~s}^{-1}\right)$ & $K_{a}\left(\mathbf{M}^{-1}\right)$ & $\begin{array}{c}\Delta H^{\circ} \\
(\mathrm{kJ} / \mathrm{mol})\end{array}$ & $\begin{array}{c}\Delta S^{\circ} \\
(\mathrm{kJ} / \mathrm{molK})\end{array}$ & $\begin{array}{c}\Delta G^{\circ} \\
(\mathrm{kJ} / \mathrm{mol})\end{array}$ \\
\hline 296 & $(1.47 \pm 0.04) \times 10^{4}$ & $2.54 \times 10^{12}$ & $(3.70 \pm 0.26) \times 10^{3}$ & & & -20.6 \\
\hline 303 & $(1.45 \pm 0.02) \times 10^{4}$ & $2.50 \times 10^{12}$ & $(1.08 \pm 0.26) \times 10^{4}$ & $149 \pm 20$ & $0.573 \pm 0.069$ & -24.6 \\
\hline 310 & $(1.33 \pm 0.02) \times 10^{4}$ & $2.30 \times 10^{12}$ & $(5.79 \pm 0.26) \times 10^{4}$ & & & -28.6 \\
\hline
\end{tabular}
Stern-Volmer binding constant $\left(K_{a}\right)$ and thermodynamic parameters $\left(\Delta H^{\circ}, \Delta S^{\circ}\right.$, and $\left.\Delta G^{\circ}\right)$ for HSA:RPF101 at 296, 303, and $310 \mathrm{~K}^{\mathrm{a}}$.

a: $r^{2}$ for $K_{S V}$ and $k_{q}: 0.9988-0.9945 ; r^{2}$ for $K_{a}: 0.9976-0.9842 ; r^{2}$ for $\Delta H^{\circ}, \Delta S^{\circ}$ and $\Delta G^{\circ}: 0.9618$. 


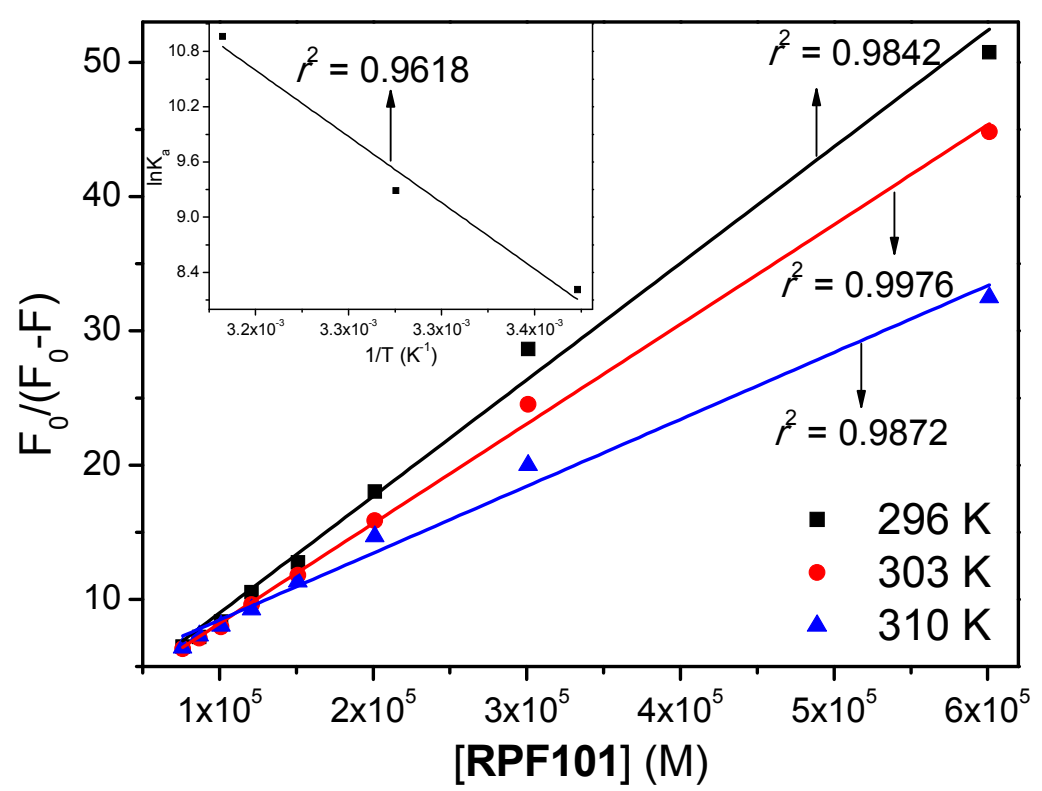

Figure 4. Modified Stern-Volmer plots for the association HSA:RPF101 in PBS solution at 296, 303 and $310 \mathrm{~K}$. Inset: Van't Hoff plot for HSA:RPF101 at three different temperatures. [HSA] $=1.00 \times 10^{-5} \mathrm{M}$ and $[$ RPF101 $]=0.17 ; 0.33 ; 0.50 ; 0.66 ; 0.83 ; 0.99 ; 1.15 ; 1.32 \times 10^{-5} \mathrm{M}$.

\subsection{Synchronous Fluorescence Spectroscopy}

In the synchronous fluorescence (SF) spectra, the sensitivity that is associated with fluorescence is maintained, while several advantages are available: spectral simplification, spectral bandwidth reduction, and avoidance of different perturbing effects [18]. By scanning the excitation and emission monochromators simultaneously, while maintaining a constant wavelength interval $(\Delta \lambda)$ between them, characteristic information about the molecular environment in the vicinity of a chromophore can be obtained [43]. The SF spectra of HSA for tyrosine $(\Delta \lambda=15 \mathrm{~nm})$ and tryptophan residues $(\Delta \lambda=60 \mathrm{~nm})$ in the presence of various concentrations of RPF101 are shown in Figure 5. This figure clearly shows that in both cases there is no significant Stokes' shift at the maximum fluorescence emission after successive additions of RPF101 to the HSA solution, suggesting that there is no significant change on the HSA structure upon ligand binding that can perturb the microenvironment around the Tyr and Trp residues $[21,44]$. 

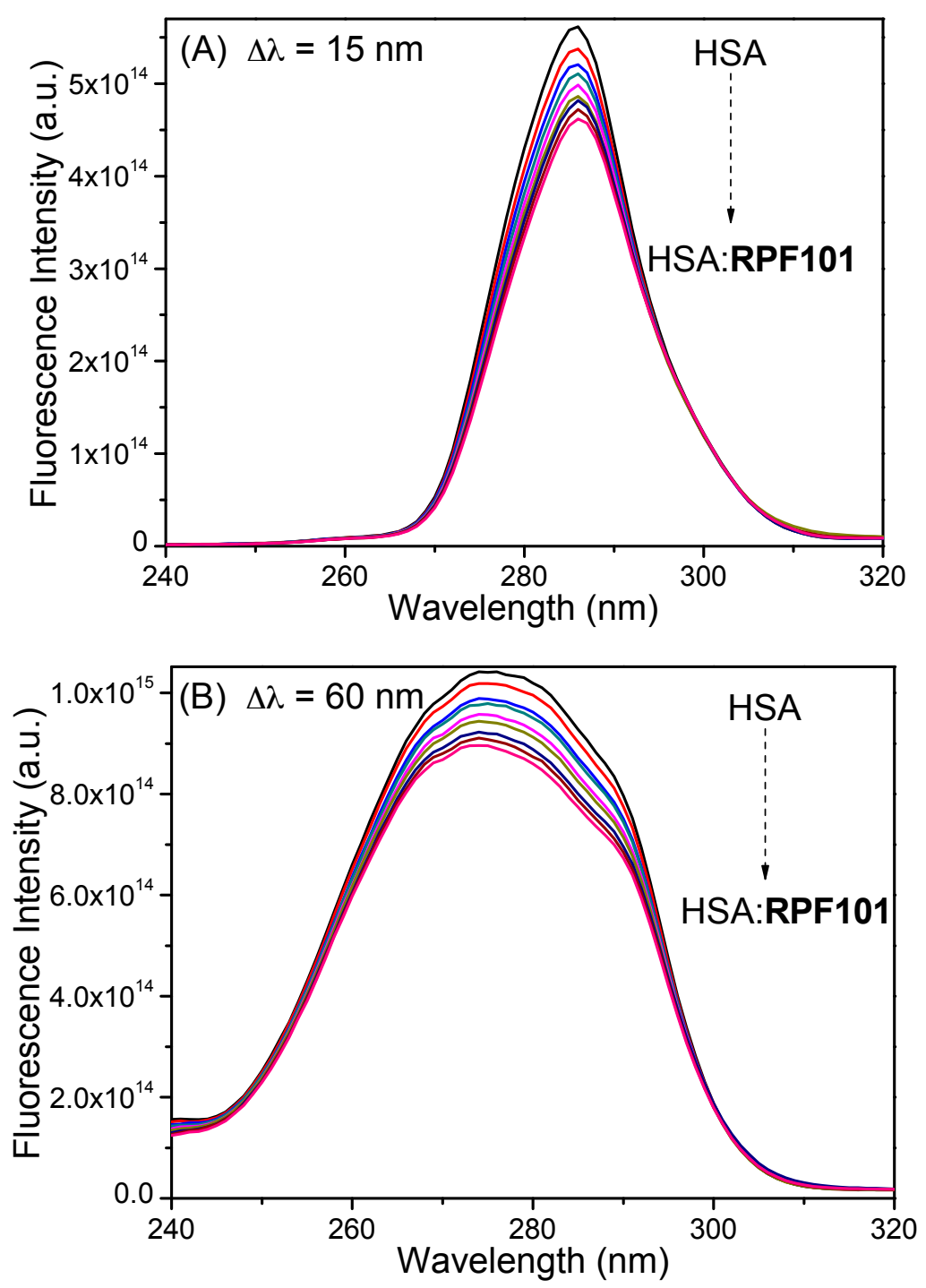

Figure 5. Synchronous fluorescence spectra for HSA without and in the presence of RPF101 at $\Delta \lambda=15 \mathrm{~nm}(\mathbf{A})$ and $\Delta \lambda=60 \mathrm{~nm}(\mathbf{B})$ in PBS solution. [HSA] $=1.00 \times 10^{-5} \mathrm{M}$ and [RPF101] $=0.17 ; 0.33$; $0.50 ; 0.66 ; 0.83 ; 0.99 ; 1.15 ; 1.32 \times 10^{-5} \mathrm{M}$.

\subsection{Zeta Potential Studies}

Changes in the zeta potential $(\mathrm{ZP}, \zeta)$ for a protein can mainly imply in conformational changes and/or unfolding/denaturation processes on the protein structure. Therefore, the ZP of a protein can be used as an indicator of the protein stability upon ligand binding [45]. The experimental ZP for free HSA was negative $(\zeta \approx-7.50 \pm 2.76 \mathrm{mV}$, conductance $\approx 30,232 \mu \mathrm{S}$, and electric field $\approx 13.60 \mathrm{~V} / \mathrm{cm})$ at $\mathrm{pH}=7.4$ in PBS buffer solution. On the other hand, upon the addition of RPF101 $\left(1.32 \times 10^{-5} \mathrm{M}\right)$, the $\mathrm{ZP}$ was $\zeta \approx-9.50 \pm 1.90 \mathrm{mV}$, conductance $\approx 28,865 \mu \mathrm{S}$, and electric field $\approx 14.30 \mathrm{~V} / \mathrm{cm}$. It is worth to note that the ZP value for HSA before and after addition of RPF101 is the same inside the experimental error of the measurements, indicating that there is no significant structural change on the protein surface upon ligand addition [46].

\subsection{Change on the Protein Secondary Structure Induced by RPF101 Binding}

Circular dichroism (CD) spectra of HSA exhibited negative bands at 208 and $222 \mathrm{~nm}$, corresponding to $\pi-\pi^{*}$ and $n-\pi^{*}$ transitions, respectively, which are characteristic of the $\alpha$-helix structure units of the protein [47]. Upon the addition of RPF101 $\left(1.32 \times 10^{-5} \mathrm{M}\right)$ to the albumin solution, a small 
decrease in the intensity of the absorptions at 208 and $222 \mathrm{~nm}$ was observed (Figure 6), indicating a very weak change on the secondary structure of HSA [48].

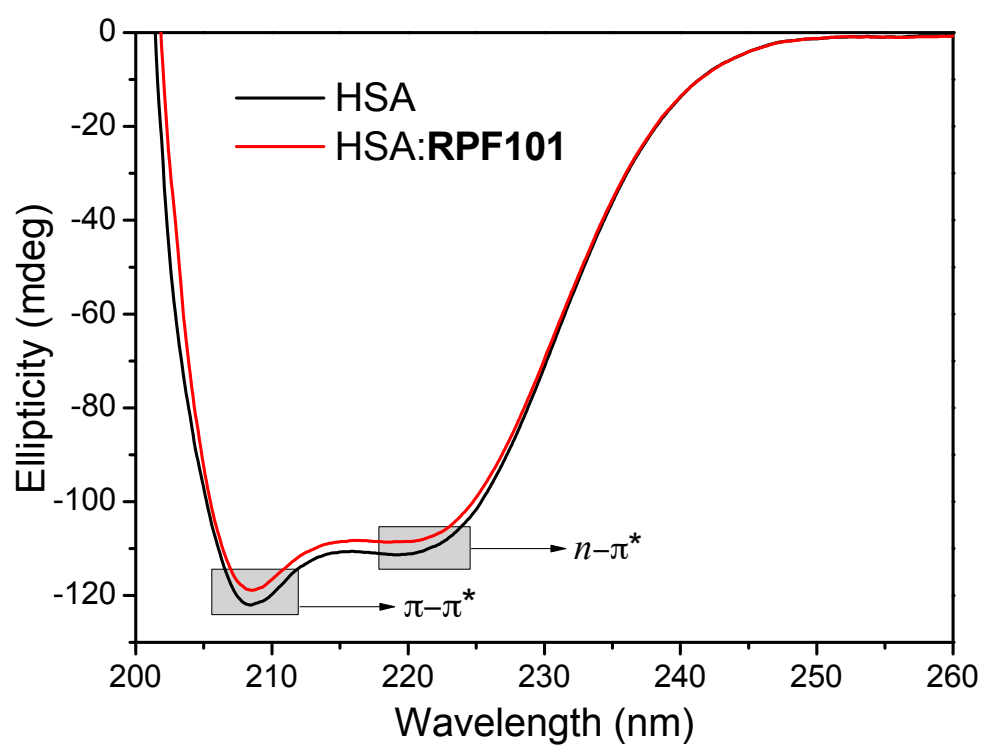

Figure 6. Circular dichroism spectra for HSA without and in the presence of RPF101 in PBS buffer solution $(\mathrm{pH}=7.4)$ at $310 \mathrm{~K}$. [HSA $]=1.00 \times 10^{-6} \mathrm{M}$ and $[$ RPF101 $]=1.32 \times 10^{-5} \mathrm{M}$.

Circular dichroism results can be expressed in terms of significant molar residual ellipticity (MRE) in $\mathrm{deg}_{\mathrm{cm}}^{2} / \mathrm{dmol}$, calculated according to Equation (7):

$$
M R E=\frac{\theta}{\left(10 \cdot n \cdot l \cdot C_{P}\right)}
$$

where, $\theta$ is the observed ellipticity (mdeg); $n$ is the number of amino acid residues (585 to HSA) [49]; $l$ is the length of the optical cuvette $(1 \mathrm{~cm})$; and $C_{p}$ is the molar concentration of HSA $\left(1.00 \times 10^{-6} \mathrm{M}\right)$. The loss of helical structure due to ligand binding can also be quantitatively calculated as contents of free and combined HSA from MRE values at 208 and $222 \mathrm{~nm}$, while applying Equations (8) and (9), respectively:

$$
\begin{aligned}
& \alpha-\text { helix } \%=\left[\frac{\left(-M R E_{208}-4000\right)}{(33000-4000)}\right] \times 100 \\
& \alpha-\text { helix } \%=\left[\frac{\left(-M R E_{222}-2340\right)}{30300}\right] \times 100
\end{aligned}
$$

where, $M R E_{208}$ and $M R E_{222}$ are the significant molar residual ellipticities $\left(\mathrm{degcm}^{2} / \mathrm{dmol}\right)$ at 208 and $222 \mathrm{~nm}$, respectively. The $\alpha$-helix content of the secondary structure of HSA in the absence of RPF101 has its maximum at about $57.5 \%$ and $53.9 \%$ at 208 and $222 \mathrm{~nm}$, respectively, while in the presence of RPF101, the $\alpha$-helix content decreased at about $55.3 \%$ and $52.1 \%$ at 208 and $222 \mathrm{~nm}$, respectively. Thus, it may be concluded from the CD results that the binding HSA:RPF101 can occur with a very weak change on the secondary structure of the protein $[36,50]$.

\subsection{Competitive Binding Studies}

In general, the main regions of small molecules binding sites on HSA are located in the hydrophobic cavities in subdomains IIA and IIIA, which are also referred as Sudlow's site I and site II, respectively, according to the terminology that was proposed by Sudlow and coworkers [51]. Furthermore, the hydrophilic cavity located in subdomain IB, which can be referred as site III, is also considered as a possible protein pocket for small molecules [18]. In order to identify the main protein 
cavity for the association HSA:RPF101, competitive binding studies were performed at $310 \mathrm{~K}$ using different site probes, like warfarin, ibuprofen, and digitoxin for sites I, II, and III, respectively [36].

The $K_{a}$ values determined by Equation (4) and Figure 7 for HSA:RPF101 in the presence of $1.00 \times 10^{-5} \mathrm{M}$ warfarin, ibuprofen, or digitoxin at $310 \mathrm{~K}$ are shown in Table 2. From the results that are shown in this table, it can be seen that the HSA:RPF101 binding in the presence of warfarin was reduced by $71.8 \%$ when compared to HSA:RPF101, without any site marker. On the other hand, in the presence of digitoxin and ibuprofen, the decrease in $K_{a}$ value was much smaller $-21.5 \%$ and $11.9 \%$, respectively. This is a clear indication that RPF101 competes with warfarin for the subdomain IIA, where the Trp-214 residue can be found $[18,21,36]$.

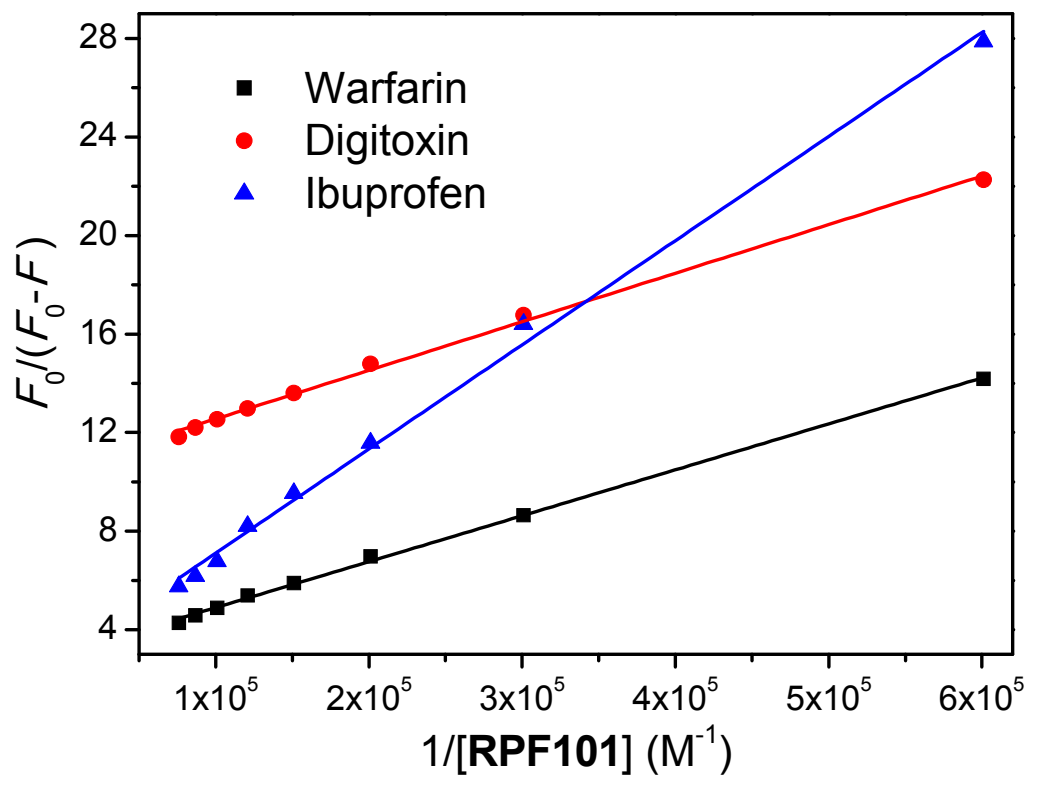

Figure 7. Modified Stern-Volmer plot for the interaction HSA:RPF101 in the presence of each site marker: warfarin, ibuprofen and digitoxin $\left(1.00 \times 10^{-5} \mathrm{M}\right)$. [HSA $]=[$ warfarin $]=[$ ibuprofen $]=$ [digitoxin] $=1.00 \times 10^{-6} \mathrm{M}$ and $\left[\right.$ RPF101] $=0.17 ; 0.33 ; 0.50 ; 0.66 ; 0.83 ; 0.99 ; 1.15 ; 1.32 \times 10^{-5} \mathrm{M}$.

Table 2. $K_{a}$ value for the interaction HSA:RPF101 without and in the presence of warfarin, ibuprofen, or digitoxin at $310 \mathrm{~K}^{\mathrm{a}}$.

\begin{tabular}{|c|c|c|c|c|}
\hline \multirow{2}{*}{ Sample } & $K_{a}\left(M^{-1}\right)$ & $K_{a}\left(M^{-1}\right)$ & $\mathrm{K}_{\mathrm{a}}\left(\mathrm{M}^{-1}\right)$ & $K_{a}\left(M^{-1}\right)$ \\
\hline & Without Site Marker & Presence Warfarin & Presence Ibuprofen & Presence Digitoxin \\
\hline RPF101 & $(5.79 \pm 0.26) \times 10^{4}$ & $(1.63 \pm 0.26) \times 10^{4}$ & $(5.10 \pm 0.26) \times 10^{4}$ & $(4.55 \pm 0.26) \times 10^{4}$ \\
\hline
\end{tabular}

\subsection{Molecular Docking Studies for the Interaction HSA:RPF101}

The spectroscopic results that are described above indicated that the main binding site for RPF101 in the HSA structure is Sudlow's site I, in subdomain IIA, where Trp-214 residue can be found. Thus, this protein pocket was chosen for performing computational experiments that aimed to provide a more detailed (atomistic view) of the binding interaction.

The molecular docking results suggested that hydrogen bonding and hydrophobic interactions are the main forces for the association HSA:RPF101 (Figure 8). Both oxygen atoms of the methylenedioxolyl moiety of RPF101 are acceptors of hydrogen bonding for arginine-221 (Arg-221) and lysine-443 (Lys-443) residues, within a distance of $2.08 \AA$ and $3.65 \AA$, respectively. The hydrogen atom of the sulfonamide linker of RPF101 is a possible donor for hydrogen bonding with the aspartic acid-450 
(Asp-450) residue within a distance of $2.10 \AA$, whereas the sulfone can interact with the hydroxyl group of the serine-453 (Ser-453) side chain via hydrogen bonding within a distance of $1.82 \AA$.

Finally, molecular docking results also suggested hydrophobic interactions via $\pi$-stacking between the Trp-214 residue and the phenyl ring of RPF101 attached to the sulfonamide linker, within a distance of $3.50 \AA$. This very same aromatic ring can interact with the amino acid residues valine-343 (Val-343) and leucine-480 (Leu-480) within distances of $2.78 \AA$ and $1.60 \AA$, respectively. Overall, the molecular docking results are in good agreement with the experimental data discussed above.

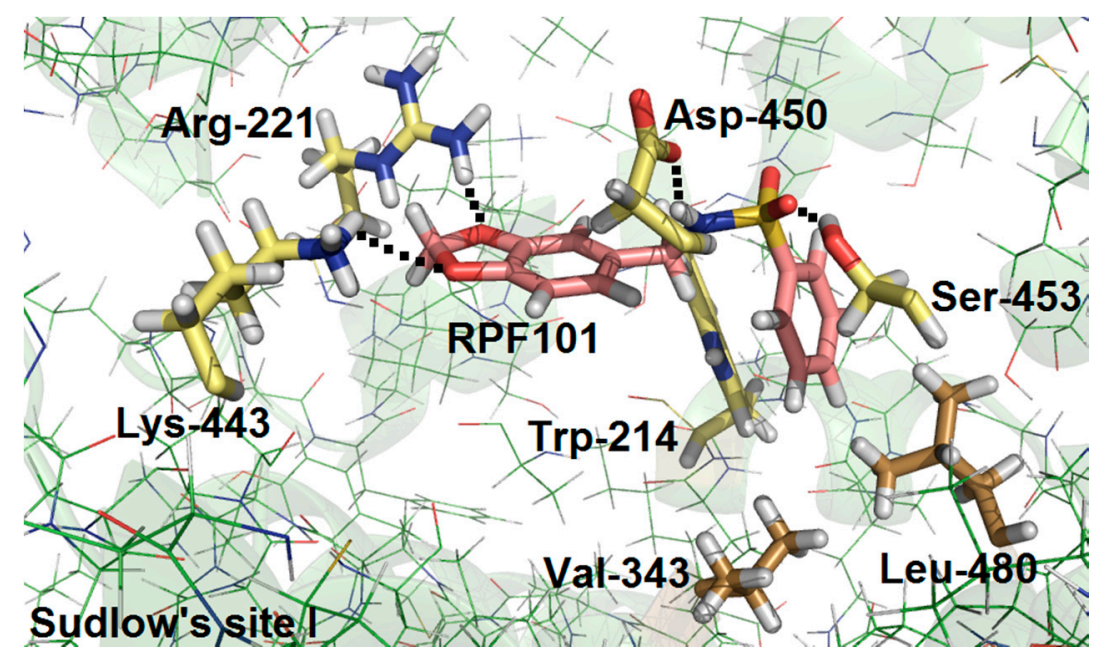

Figure 8. The best score pose for the interaction HSA:RPF101 in Sudlow's site I, as obtained by molecular docking (ChemPLP function). RPF101 structure, selected hydrophilic and hydrophobic amino acid residues are represented in beige, yellow and brown, respectively. Green color is the HSA structure (PDB:1N5U). Elements colors: hydrogen, oxygen, nitrogen, and sulfur are represented in white, red, blue, and goldenrod, respectively. Arginine: Arg; aspartic acid: Asp; lysine: Lys; tryptophan: Trp; serine: Ser; leucine: Leu; valine: Val.

\section{Discussion}

In the literature, there is a reasonable amount or work describing the interaction between HSA:natural products and HSA:natural products analogues, such as mangiferin [52], kaempferol [49], wogonin [39], pheophytin [26], and flanovoids [21,53]. In the case of natural products that are extracted from peppers and its analogues, it was only explored the interaction between serum albumin and 1-piperoyl piperidine (piperine) [54,55]. Since there are few investigations on the interaction between serum albumin and natural products analogues from peppers components, as well as the application of multi-spectroscopic techniques combined with theoretical methods can be used as an initial process for the evaluation of some pharmacokinetic profile of potential drugs, the present discussion is focused on the interaction HSA:RFP101 by circular dichroism, steady-state, time-resolved, and synchronous fluorescence combined with zeta potential and theoretical calculations.

The Stern-Volmer analysis applied in the steady-state fluorescence data indicated a decrease in the $K_{S V}$ values with increasing of temperature and the $k_{q}$ values are three orders of magnitude higher than $k_{\text {diff. }}$. These observations can indicate a ground state association between HSA and RPF101 (static fluorescence quenching mechanism). To get more insight into the fluorescence mechanism of RPF101 to serum albumin, the time-resolved fluorescence technique was employed. This technique revealed that the fluorescence decays for HSA are composed by two different lifetimes being the second one the most contribution. Since the fluorescence lifetimes for HSA without and in the presence of the ligand (RPF101) are the same inside the experimental error, i.e., $\tau_{2}=5.78 \pm 0.15$ and $\tau_{2}=5.72 \pm 0.13 \mathrm{~ns}$, respectively, the static fluorescence quenching mechanism can be confirmed. 
The binding affinity of any substance to serum albumin is one of the major factors that determine the pharmacokinetics i.e., time course of drug absorption, distribution, metabolism, and excretion. Since the modified Stern-Volmer binding constant values are in the order of $10^{3}-10^{4} \mathrm{M}^{-1}$, there is an indicative of moderate binding affinity between HSA and RPF101 [56]. Since, $\Delta G^{\circ}$ values for the interaction HSA:RPF101 are negative, thus indicating a spontaneous process. The positive values for $\Delta H^{\circ}$ and $\Delta S^{\circ}$ are indicative of a binding process that is controlled by entropy [31]. According to the Gibbs free energy equation, a positive enthalpy change is not favorable for the spontaneity of the binding process, unlike a positive entropy change that leads to a more negative value for the Gibbs free energy. From Ross and Subramanian theory [41] positive values for enthalpy and entropy change suggest hydrophobic interaction as the main intermolecular force that is involved in the binding process. These association parameters indicated that RPF101 presented similar binding ability toward HSA when compared to piperine [55].

The steady-state fluorescence spectrum of HSA presented maximum fluorescence emission at $340 \mathrm{~nm}$. Upon successive additions of RPF101 to HSA solution fluorescence quenching can be observed without any blue or red shift (Stokes' shift), indicating that the ligand binding does not perturb significantly the fluorophore environment $[21,22]$. In order to confirm this result, synchronous fluorescence (SF) spectra was carried out at $\Delta \lambda=15$ and $60 \mathrm{~nm}$. In the SF spectra, a decrease in fluorescence intensity without any shift is an indicative that there is no significant changes on the HSA structure upon ligand binding, which can perturb the microenvironment around Tyr and Trp residues [18].

The binding of RPF101 to HSA structure could cause some modifications on the surface and secondary structure of the albumin, which could reflect in an inactivation of the protein activity. According to zeta potential results $(\zeta \approx-7.50 \pm 2.76$ and $-9.50 \pm 1.90 \mathrm{mV}$, for HSA and HSA:RPF101, respectively), there is a clear indication that the binding of the ligand does not perturb the protein surface ( $\zeta$ without and in the presence of RPF101 are the same inside the experimental error) [46]. Circular dichroism results indicated a very weak perturbation on the secondary structure of the albumin upon ligand binding (variation of $2.20 \%$ and $1.80 \%$ at 208 and $222 \mathrm{~nm}$, respectively) [37]. Thus, besides the presence of the capsaicin analogue does not perturb the microenvironment around Trp and Tyr residues it does not significantly perturb the surface and secondary structure of the albumin.

HSA structure has three main binding sites, which are located in the subdomain IIA (site I), IIIA (site II), and IB (site III) [51,56]. Competitive binding studies in the presence of three commercial site markers (warfarin, ibuprofen, and digitoxin) suggested site I, which is also known as Sudlow's site I, as the main protein binding pocket for RPF101 $\left(K_{a}\right.$ value without and in the presence of warfarin changed $71.8 \%$ at $310 \mathrm{~K}$ ). The same binding pocket was also identified for piperine, which has the same (1,3)-benzodioxolyl moiety and close ClogP values (theoretical octanol/water partition coefficient) as compared to RPF101 (2.15 and 2.78, respectively) [4,55]. In order to offer an atomic view of the interaction HSA:RPF101, theoretical calculations via molecular docking were carried out. Molecular docking results suggested hydrophobic interactions and hydrogen bonding as the main binding forces in the association HSA:RPF101 in the subdomain IIA. There are chemical groups in the ligand structure that are possible acceptors for hydrogen bonding with Arg-221, Lys-443, and Ser-453 residues. On the other hand, the amino acid residue Asp-450 is a potential acceptor for hydrogen bonding with the ligand structure. Finally, hydrophobic interactions were also suggested between RPF101 and three amino acid residues: Trp-214, Val-343, and Leu-480. Note that the experimental data obtained from steady-state fluorescence measurements indicated the interaction HSA:RPF101 as essentially entropically driven, while molecular docking results, which give evidences from an atomic point of view, suggested entropic and enthalpic contributions. Thus, RPF101 can interact with albumin essentially controlled by entropic effects, however, the enthalpic contribution can also be involved in this association. Overall, the capsaicin analogue presented good binding ability toward HSA, indicating high probability to be carried in the human bloodstream. 


\section{Conclusions}

Fluorescence quenching studies of HSA by RPF101 showed $K_{S V}$ and $k_{q}$ values that led us to conclude that the fluorescence quenching occurs via a static mechanism, which indicates the presence of a ground state association HSA:RPF101. This conclusion was supported by time-resolved fluorescence results. The interaction HSA:RPF101 is moderate $\left(K_{a} \approx 10^{3}-10^{4} \mathrm{M}^{-1}\right)$, entropically driven, spontaneous and does not significantly change the potential surface of the protein, as well as the environment around tyrosine and tryptophan residues. The CD results indicated that upon ligand binding there is a very weak perturbation on the secondary structure of the albumin. Competitive binding studies indicated Sudlow's site I-located in the subdomain IIA—as the main protein pocket for this association. Molecular docking results suggested that the ligand interacts via hydrogen bonding with Arg-221, Lys-443, Asp-450, and Ser-453 residues and also via hydrophobic interactions with Trp-214, Val-343, and Leu-480 residues. At comparing spectroscopic and molecular docking results the interaction HSA:RPF101 is essentially controlled by entropic effects, however, the enthalpic contribution can also be an evidences involved in this association. Overall, the potential drug RPF101 can be carried and distributed by HSA in the human bloodstream.

Supplementary Materials: The following are available online at http://www.mdpi.com/2218-273X/8/3/ 78/s1, Figure S1: UV-Vis spectra for HSA and RPF101 in PBS solution. [HSA] $=1.00 \times 10^{-5} \mathrm{M}$ and $\left[\right.$ RPF101] $=1.32 \times 10^{-5} \mathrm{M}$. Figure S2: (A) Steady-state fluorescence emission spectra for HSA without and in the presence of $40 \mu \mathrm{L}$ of methanol at $310 \mathrm{~K}$. (B) CD spectra for HSA without and in the presence of $40 \mu \mathrm{L}$ of methanol at $310 \mathrm{~K}$. Figure S3: Overlap between UV-Vis spectrum of RPF101 and steady-state fluorescence emission spectrum of HSA at $310 \mathrm{~K}$. [HSA $]=[$ RPF101 $]=1.00 \times 10^{-5} \mathrm{M}$.

Author Contributions: O.A.C. conducted spectroscopic, zeta potential and molecular docking experiments. M.T.T. and M.R.C. conducted the synthesis of RPF101. C.M.R.S. professor responsible for the molecular docking analysis. J.C.N.-F. professor responsible for the spectroscopic analysis. R.P.-F. professor responsible for the synthesis. All authors contributed for the written of the manuscript.

Funding: This research was funded by the Brazilian agencies: Coordenação de Aperfeiçoamento de Pessoal de Nível Superior (CAPES), Conselho Nacional de Desenvolvimento Científico e Tecnológico (CNPq), Fundação de Amparo à Pesquisa do Estado do Rio de Janeiro (FAPERJ), and Fundação de Amparo à Pesquisa do Estado de São Paulo (FAPESP, Process: 2017/00689-0).

Acknowledgments: A special acknowledgement is given to Nanci Câmara de Lucas Garden from Department of Organic Chemistry at UFRJ-Brazil for the time-resolved and synchronous fluorescence facilities. The authors also thank Paloma Wetler Meireles and Lucio Mendes Cabral from Laboratório de Tecnologia Industrial Farmacêutica. (LabTIF/UFRJ) for making available the zeta potential facilities as well as for their active help during the experimental measurements. The author O.A.C. acknowledges Instituto Euvaldo Lodi (IEL-Brazil) for a scholarship (Encomenda Rhae-SENAI Innovation Institute for Green Chemistry-Trainee II-404988/2017-2-Process: 350173/2018-4). Authors M.T.T., M.R.C. and R.P.-F. acknowledge Elizabeth Ignes Ferreira from Department of Pharmacy (Lapen/FCF-USP) for making available the Isolera ${ }^{\mathrm{TM}}$ Prime equipment employed for the purification of RPF101.

Conflicts of Interest: The authors declare no conflict of interest.

\section{References}

1. Clark, R.; Lee, S. Anticancer properties of capsaicin against human cancer. Anticancer Res. 2016, 36, 837-844. [PubMed]

2. Lee, J.H.; Lee, Y.; Ryu, H.C.; Kang, D.W.; Lee, J.; Lazar, J.; Pearce, L.V.; Pavlyukovets, V.A.; Blumberg, P.M.; Choi, S. Structural insights into transient receptor potential vanilloid type 1 (TRPV1) from homology modeling, flexible docking, and mutational studies. J. Comput. Aided Mol. Des. 2011, 25, 317-327. [CrossRef] [PubMed]

3. Yong, Y.L.; Tan, L.T.H.; Ming, L.C.; Chan, K.G.; Lee, L.H.; Goh, B.H.; Khan, T.M. The effectiveness and safety of topical capsaicin in postherpetic neuralgia: A systematic review and meta-analysis. Front. Pharmacol. 2017, 7, 538. [CrossRef] [PubMed] 
4. Sá-Júnior, P.L.; Pasqualoto, K.F.M.; Ferreira, A.K.; Tavares, M.T.; Damião, M.C.F.C.B.; De Azevedo, R.A.; Câmara, D.A.D.; Pereira, A.; Souza, D.M.; Parise-Filho, R. RPF101, a new capsaicin-like analogue, disrupts the microtubule network accompanied by arrest in the G2/M phase, inducing apoptosis and mitotic catastrophe in the MCF-7 breast cancer cells. Toxicol. Appl. Pharmacol. 2013, 266, 385-398. [CrossRef] [PubMed]

5. Damião, M.C.; Pasqualoto, K.F.; Ferreira, A.K.; Teixeira, S.F.; Azevedo, R.A.; Barbuto, J.A.; Berl, F.P.; Franchi-Junior, G.C.; Nowill, A.E.; Tavares, M.T.; et al. Novel capsaicin analogues as potential anticancer agents: Synthesis, biological evaluation, and In silico approach. Archiv der Pharmazie 2014, 347, 885-895. [CrossRef] [PubMed]

6. Tavares, M.T.; Pasqualoto, K.F.M.; Van de Streek, J.; Ferreira, A.K.; Azevedo, R.A.; Damião, M.C.F.C.B.; Rodrigues, C.P.; de-Sá-Júnior, P.L.; Barbuto, J.A.M.; Parise-Filho, R.; et al. Synthesis, characterization, in silico approach and in vitro antiproliferative activity of RPF151, a benzodioxole sulfonamide analogue designed from capsaicin scaffold. J. Mol. Struct. 2015, 1088, 138-146. [CrossRef]

7. Ferreira, A.K.; Tavares, M.T.; Pasqualoto, K.F.M.; Azevedo, R.A.; Teixeira, S.F.; Ferreira-Junior, W.A.; Bertin, A.M.; de-Sá-Junior, P.L.; Barbuto, J.A.M.; Figueiredo, C.R.; et al. RPF151, a novel capsaicin-like analogue: In vitro studies and in vivo preclinical antitumor evaluation in a breast cancer model. Tumor Biol. 2015, 36, 7251-7267. [CrossRef] [PubMed]

8. Peters, T. Serum albumin. Adv. Protein Chem. 1985, 37, 161-245. [PubMed]

9. Yeggoni, D.P.; Gokara, M.; Manidhar, D.M.; Rachamallu, A.; Nakka, S.; Reddy, C.S.; Subramanyam, R. Binding and molecular dynamics studies of 7-hydroxycoumarin derivatives with human serum albumin and its pharmacological importance. Mol. Pharm. 2014, 11, 1117-1131. [CrossRef] [PubMed]

10. Carter, D.C.; Ho, J.X. Structure of serum albumin. Adv. Protein Chem. 1994, 45, 153-203. [PubMed]

11. Carter, D.C.; He, X.-M.; Munson, S.H.; Twigg, P.D.; Gernert, K.M.; Broom, M.B.; Miller, T.Y. Three-dimensional structure of human serum albumin. Science 1989, 244, 1195-1198. [CrossRef] [PubMed]

12. Shahsavani, M.B.; Ahmadi, S.; Aseman, M.D.; Nabavizadeh, S.M.; Alavianmehr, M.M.; Yousef, R. Comparative study on the interaction of two binuclear Pt (II) complexes with human serum albumin: Spectroscopic and docking simulation assessments. J. Photochem. Photobiol. B Biol. 2016, 164, 323-334. [CrossRef] [PubMed]

13. Kratz, F. Albumin as a drug carrier: Design of prodrugs, drug conjugates and nanoparticles. J. Control. Release 2008, 132, 171-183. [CrossRef] [PubMed]

14. Danhier, F.; Feron, O.; Préat, V. To exploit the tumor microenvironment: Passive and active tumor targeting nanocarriers for anti-cancer drug delivery. J. Control. Release 2010, 148, 135-146. [CrossRef] [PubMed]

15. Desai, N.; Trieu, V.; Yao, Z.; Louie, L.; Ci, S.; Yang, A.; Tao, C.; De, T.; Beals, B.; Dykes, D.; et al. Increased antitumor activity, intratumor paclitaxel concentrations, and endothelial cell transport of cremophor-free, albumin-bound paclitaxel, ABI-007, compared with cremophor-based paclitaxel. Clin. Cancer Res. 2006, 12, 1317-1324. [CrossRef] [PubMed]

16. Shao, X.; Ai, N.; Xu, D.; Fan, X. Exploring the interaction between Salvia miltiorrhiza and human serum albumin: Insights from herb-drug interaction reports, computational analysis and experimental studies. Spectrochim. Acta Mol. Biomol. Spectrosc. 2016, 161, 1-7. [CrossRef] [PubMed]

17. Chaves, O.A.; Jesus, C.S.H.; Cruz, P.F.; Sant'Anna, C.M.R.; Brito, R.M.M.; Serpa, C. Evaluation by fluorescence, STD-NMR, docking and semi-empirical calculations of the $o$-NBA photo-acid interaction with BSA. Spectrochim. Acta Mol. Biomol. Spectrosc. 2016, 169, 175-181. [CrossRef] [PubMed]

18. Sun, Z.; Xu, H.; Cao, Y.; Wang, F.; Mi, W. Elucidating the interaction of propofol and serum albumin by spectroscopic and docking methods. J. Mol. Liq. 2016, 219, 405-410. [CrossRef]

19. Wardell, M.; Wang, Z.; Ho, J.X.; Robert, J.; Ruker, F.; Ruble, J.; Carter, D.C. The atomic structure of human methemalbumin at 1.9 Å. Biochem. Biophys. Res. Commun. 2002, 291, 813-819. [CrossRef] [PubMed]

20. The Cambridge Crystallographic Data Centre (CCDC). Available online: http://www.ccdc.cam.ac.uk/ solutions / csd-discovery/components/gold/ (accessed on 5 July 2018).

21. Chaves, O.A.; Cesarin-Sobrinho, D.; Sant'Anna, C.M.R.; de Carvalho, M.G.; Suzart, L.R.; Catunda-Junior, F.E.A.; Netto-Ferreira, J.C.; Ferreira, A.B.B. Probing the interaction between 7-O- $\beta$-D-glucopyranosyl-6-(3-methylbut-2-enyl)-5,4'-dihydroxyflavonol with bovine serum albumin (BSA). J. Photochem. Photobiol. A Chem. 2017, 336, 32-41. [CrossRef] 
22. Chaves, O.A.; Santos, M.R.L.; Oliveira, M.C.C.; Sant'Anna, C.M.R.; Ferreira, R.C.; Echevarria, A.; Netto-Ferreira, J.C. Synthesis, tyrosinase inhibition and transportation behavior of novel $\beta$-enamino thiosemicarbazide derivatives by human serum albumin. J. Mol. Liq. 2018, 254, 280-290. [CrossRef]

23. Lakowicz, J.R. Principles of Fluorescence Spectroscopy, 1st ed.; Springer: New York, NY, USA, 2006; ISBN 978-0-387-31278-1.

24. Alam, P.; Abdelhameed, A.S.; Rajpoot, R.K.; Khan, R.H. Interplay of multiple interaction forces: Binding of tyrosine kinase inhibitor nintedanib with human serum albumin. J. Photochem. Photobiol. B Biol. 2016, 157, 70-76. [CrossRef] [PubMed]

25. Liu, F.; Wang, Y.; Lv, C.; Wang, L.; Ou, J.; Wang, M.; Liu, S. Impact of halogen substituents on interactions between 2-phenyl-2,3-dihydroquinazolin-4(1H)-one derivatives and human serum albumin. Molecules 2012, 17, 2000-2014. [CrossRef] [PubMed]

26. Chaves, O.A.; Amorim, A.P.O.; Castro, L.H.E.; Sant'Anna, C.M.R.; de Oliveira, M.C.C.; Cesarin-Sobrinho, D.; Netto-Ferreira, J.C.; Ferreira, A.B.B. Fluorescence and docking studies of the interaction between human serum albumin and pheophytin. Molecules 2015, 20, 19526-19539. [CrossRef] [PubMed]

27. Montalti, M.; Credi, A.; Prodi, L.; Gandolfi, M.T. Handbook of Photochemistry, 3rd ed.; CRC Press: Boca Raton, FL, USA; Taylor \& Francis: Didcot, UK, 2006; pp. 415-466. ISBN 9780824723774.

28. Chaves, O.A.; Soares, B.A.; Maciel, M.A.M.; Sant'Anna, C.M.R.; Netto-Ferreira, J.C.; Cesarin-Sobrinho, D.; Ferreira, A.B.B. A study of the interaction between trans-dehydrocrotonin, a bioactive natural 19-nor-clerodane, and serum albumin. J. Braz. Chem. Soc. 2016, 27, 1858-1865.

29. Molina-Bolívar, J.A.; Ruiz, C.C.; Galisteo-González, F.; Donnell, M.M.-O.; Parra, A. Simultaneous presence of dynamic and sphere action component in the fluorescence quenching of human serum albumin by diphthaloylmaslinic acid. J. Lumin. 2016, 178, 259-266. [CrossRef]

30. Sun, H.; Liu, Y.; Li, M.; Han, S.; Yang, X.; Liu, R. Toxic effects of chrysoidine on human serum albumin: Isothermal titration calorimetry and spectroscopic investigations. Luminescence 2016, 31, 335-340. [CrossRef] [PubMed]

31. Chaves, O.A.; Mathew, B.; Joy, M.; Lohidakshan, K.K.; Marathakam, A.; Netto-Ferreira, J.C. Introduction of fluorinated environment on metformin. Evaluation of its serum-albumin interaction with molecular modeling studies. J. Mol. Liq. 2018, 260, 186-194. [CrossRef]

32. Bi, S.; Zhao, T.; Zhou, H.; Wang, Y.; Li, Z. Probing the interactions of bromchlorbuterol- $\mathrm{HCl}$ and phenylethanolamine A with HSA by multi-spectroscopic and molecular docking technique. J. Chem. Thermodyn. 2016, 97, 113-121. [CrossRef]

33. Turro, N.J. Modern Molecular Photochemistry, 1st ed.; University Science Books: Sausalito, CA, USA, 1991; ISBN 978-0-935702-7-12.

34. Wang, Q.; Liu, X.; Su, M.; Shi, Z.; Sun, H. Study on the interaction characteristics of cefamandole with bovine serum albumin by spectroscopic technique. Spectrochim. Acta Mol. Biomol. 2015, 136, 321-326. [CrossRef] [PubMed]

35. Chaves, O.A.; Jesus, C.S.H.; Henriques, E.S.; Brito, R.M.M.; Serpa, C. In-situ ultra-fast heat deposition does not perturb serum albumin structure. Photochem. Photobiol. Sci. 2016, 15, 1524-1535. [CrossRef] [PubMed]

36. Rehman, M.T.; Shamsi, H.; Khan, A.U. Insight into the binding mechanism of imipenem to human serum albumin by spectroscopic and computational approaches. Mol. Pharm. 2014, 11, 1785-1797. [CrossRef] [PubMed]

37. Chaves, O.A.; Mathew, B.; Cesarin-Sobrinho, D.; Lakshminarayanan, B.; Joy, M.; Mathew, G.E.; Suresh, J.; Netto-Ferreira, J.C. Spectroscopic, zeta potential and molecular docking analysis on the interaction between human serum albumin and halogenated thienyl chalcones. J. Mol. Liq. 2017, 242, 1018-1026. [CrossRef]

38. Zhu, Y.; Zhang, R.; Wang, Y.; Ma, J.; Li, K.; Li, Z. Biophysical study on the interaction of an anesthetic, vecuronium bromide with human serum albumin using spectroscopic and calorimetric methods. J. Photochem. Photobiol. B Biol. 2014, 140, 381-389. [CrossRef] [PubMed]

39. Tian, J.N.; Liu, J.; Hu, Z.D.; Chen, X.G. Interaction of wogonin with bovine serum albumin. Bioorg. Med. Chem. 2005, 13, 4124-4129. [CrossRef] [PubMed]

40. Zhang, H.-X.; Xiong, H.-X.; Li, L.-W. Investigation on the protein-binding properties of icotinib by spectroscopic and molecular modeling method. Spectrochim. Acta Mol. Biomol. Spectrosc. 2016, 161, 88-94. [CrossRef] [PubMed] 
41. Ross, P.D.; Subramanian, S. Thermodynamics of protein association reactions: Forces contributing to stability. Biochemistry 1981, 20, 3096-3102. [CrossRef] [PubMed]

42. De Barros, L.S.; Chaves, O.A.; Schaeffer, E.; Sant'Anna, C.M.R.; Ferreira, A.B.B.; Cesarin-Sobrinho, D.; da Silva, F.A.; Netto-Ferreira, J.C. Evaluating the interaction between di-fluorinated chalcones and plasmatic albumin. J. Fluor. Chem. 2016, 190, 81-88. [CrossRef]

43. Vignesh, G.; Sugumar, K.; Arunachalam, S.; Vignesh, S.; James, R.A.; Arun, R.; Premkumar, K. Studies on the synthesis, characterization, human serum albumin binding and biological activity of single chain surfactant-cobalt(III) complexes. Luminescence 2016, 31, 523-532. [CrossRef] [PubMed]

44. Barakat, C.; Patra, D. Combining time-resolved fluorescence with synchronous fluorescence spectroscopy to study bovine serum albumin-curcumin complex during unfolding and refolding processes. Luminescence 2013, 28, 149-155. [CrossRef] [PubMed]

45. Hosainzadeh, A.; Gharanfoli, M.; Saberi, M.R.; Chamani, J.K. Probing the interaction of human serum albumin with bilirubin in the presence of aspirin by multi-spectroscopic, molecular modeling and zeta potential techniques: Insight on binary and ternary systems. J. Biomol. Struct. Dyn. 2012, 29, 1013-1050. [CrossRef] [PubMed]

46. Zhang, S.; Chen, X.; Ding, S.; Lei, Q.; Fang, W. Unfolding of human serum albumin by gemini and single-chain surfactants: A comparative study. Colloids Surf. A 2016, 495, 30-38. [CrossRef]

47. Rastegari, B.; Karbalaei-Heidari, H.R.; Yousefi, R.; Zeinali, S.; Nabavizadeh, M. Interaction of prodigiosin with HSA and $\beta$-Lg: Spectroscopic and molecular docking studies. Bioorg. Med. Chem. 2016, 24, 1504-1512. [CrossRef] [PubMed]

48. Qian, Y.; Zhou, X.; Chen, J.; Zhang, Y. Binding of bezafibrate to human serum albumin: Insight into the non-covalent interaction of an emerging contaminant with biomacromolecules. Molecules 2012, 17, 6821-6831. [CrossRef] [PubMed]

49. Matei, I.; Hillebrand, M. Interaction of kaempferol with human serum albumin: A fluorescence and circular dichroism study. J. Pharm. Biomed. Anal. 2010, 51, 768-773. [CrossRef] [PubMed]

50. Rabbani, G.; Baig, M.H.; Lee, E.J.; Cho, W.K.; Ma, J.Y.; Choi, I. Biophysical study on the interaction between eperisone hydrochloride and human serum albumin using spectroscopic, calorimetric, and molecular docking analysis. Mol. Pharm. 2017, 14, 1656-1665. [CrossRef] [PubMed]

51. Sudlow, G.; Birkett, D.J.; Wade, D.N. Further characterization of specific drug binding sites on human serum albumin. Mol. Pharmacol. 1976, 12, 1052-1061. [PubMed]

52. Yue, Y.; Chen, X.; Qin, J.; Yao, X. Characterization of the mangiferin-human serum albumin complex by spectroscopic and molecular modeling approaches. J. Pharm. Biomed. Anal. 2009, 49, 753-759. [CrossRef] [PubMed]

53. Wang, B.; Qin, Q.; Chang, M.; Li, S.; Shi, X.; Xu, G. Molecular interaction study of flavonoids with human serum albumin using native mass spectrometry and molecular modeling. Anal. Bioanal. Chem. 2018, 410, 827-837. [CrossRef] [PubMed]

54. Yeggoni, D.P.; Rachamallu, A.; Kallubai, M.; Subramanyam, R. Cytotoxicity and comparative binding mechanism of piperine with human serum albumin and $\alpha$-1-acid glycoprotein. J. Biomol. Struct. Dyn. 2015, 33, 1336-1351. [CrossRef] [PubMed]

55. Suresh, D.V.; Mahesha, H.G.; Rao, A.G.A.; Srinivasan, K. Binding of bioactive phytochemical piperine with human serum albumin: A spectrofluorometric study. Biopolymers 2007, 84, 265-275. [CrossRef] [PubMed]

56. Naveenraj, S.; Anandan, S. Binding of serum albumins with bioactive substances-Nanoparticles to drugs. J. Photochem. Photobiol. C Rev. 2013, 14, 53-71. [CrossRef]

(C) 2018 by the authors. Licensee MDPI, Basel, Switzerland. This article is an open access article distributed under the terms and conditions of the Creative Commons Attribution (CC BY) license (http:/ / creativecommons.org/licenses/by/4.0/). 